\title{
Caracterização morfológica e dissimilaridade genética entre variedades crioulas de melão
}

\author{
Raquel Silviana Neitzke'; Rosa Lía Barbieri²; Gustavo Heiden³; Miriam V Büttow ${ }^{4}$; Clarisse S Oliveira ${ }^{5}$; \\ Lauís B Corrêa $^{6}$; José Ernani Schwengber ${ }^{2}$; Fernando IF de Carvalho ${ }^{7}$ \\ ${ }^{1}$ Doutoranda em Agronomia, UFPel; ${ }^{2}$ Embrapa Clima Temperado, C. Postal 403, 96001-970 Pelotas-RS; ${ }^{3}$ Mestrando em Botânica, Jardim \\ Botânico do Rio de Janeiro; ${ }^{4}$ Doutoranda em Genética e Biologia Molecular, UFGRS; ${ }^{5}$ Mestranda em Agronomia, UFSM; ${ }^{6}$ Biólogo, \\ Pelotas; ${ }^{7}$ UFPel-FAM, Dep ${ }^{\text {to }}$ Fitotecnia, C. Postal 354, Pelotas-RS; raquelsilviana@gmail.com
}

\begin{abstract}
RESUMO
Variedades crioulas de melão (Cucumis melo) são cultivadas no Sul do Brasil para consumo familiar e também para comercialização dos frutos. No entanto, existe uma carência de trabalhos relativos a sua caracterização. Este trabalho teve por objetivo caracterizar e avaliar a variabilidade genética de variedades crioulas de melão do Sul do Brasil mantidos no Banco Ativo de Germoplasma de Cucurbitáceas da Embrapa Clima Temperado. Foram caracterizados 14 acessos utilizando 26 descritores morfológicos de fruto. Os dados foram analisados pelos métodos de agrupamento de Tocher e hierárquico UPGMA. Os métodos de agrupamento foram parcialmente concordantes. O acesso C88 possui características distintas, ficando isolado dos demais, pois é o único entre todos os avaliados que apresenta formato piriforme e sem gomos, cor de epicarpo creme, cor de polpa branca e ruptura profunda no fruto. Existe grande variabilidade genética, para caracteres de frutos, nas variedades crioulas de melão conservadas nesse Banco Ativo de Germoplasma, com potencial para uso no melhoramento genético, destacando-se o acesso C71 por possuir sabor adocicado e polpa de cor laranja e o C72, por apresentar elevados valores de peso de fruto e espessura de polpa.
\end{abstract}

Palavras-chave: Cucumis melo, variabilidade genética, recursos genéticos, descritores, germoplasma.

\begin{abstract}
Morphological characterization and genetic dissimilarity in melon landraces

Melon landraces (Cucumis melo) are cultivated in South of Brazil for family consumption and also for marketing fruits. However, there is a lack of works related to characterization of these landraces. The objective of this work was to characterize and evaluate genetic variability of melon landraces from South of Brazil which are maintained in the Cucurbitaceae Genebank at Embrapa Clima Temperado, trough morphological characterization. Fourteen accessions were characterized in 26 morphological fruit descriptors. Data were analyzed by Tocher grouping method and UPGMA hierarchical. The two methods agreed partially. The accession C88 has unique characteristics, being isolated when compared to the other accessions, it is the only one among all evaluated with pyriform shape and fruit ribs absent, cream skin color, white flesh color and deep groove in the fruit. There is great genetic variability for fruit traits in the melon landraces from South of Brazil maintained in this Gene Bank, with potential use in plant breeding, with an emphasis on the accession C71 due to its sweet taste and orange pulp and the C72 due to its high values for fruit weight and flesh thickness.
\end{abstract}

Keywords: Cucumis melo, genetic variability, genetic resources, descriptors, germplasm.

(Recebido para publicação em 25 de julho de 2008; aceito em 28 de agosto de 2009) (Received in July 25, 2008; accepted in August 28, 2009)

$\mathrm{O}$ melão é uma das espécies de maior importância econômica da família Cucurbitaceae. Possui grande variabilidade genética em relação a diversos caracteres, como comprimento dos ramos variando de um a 10 metros, com peso de frutos variando de 10 gramas até 10 quilogramas, teor de sólidos solúveis variando entre 3 e $18 \%$ e acidez da polpa com $\mathrm{pH}$ variando de 3 a 7 (Paiva, 1999).

A importância econômica do melão no Brasil vem aumentando, em virtude principalmente das exportações (Santos et al., 2004). Para aumentar a competição no mercado internacional é necessário dispor de cultivares bem adaptadas, resistentes a pragas e doenças e que produzam frutos de alta qualidade.

Para o mercado internacional do melão existem requerimentos de qualidade definidos por critérios nutricionais, higiênicos, tecnológicos e sensoriais que influenciam a aceitação do consumidor, além de resistência ao manuseio, transporte e armazenamento, que determinam o preço recebido pelo produto (Miranda et al., 2005).

No cultivo do melão são utilizadas principalmente sementes de cultivares comerciais e híbridos, geralmente importadas, visando principalmente o mercado para exportação e buscando atender a demanda da população brasi- leira que exige frutos de boa qualidade (Lopes et al., 1999).

O preço elevado cobrado pela semente de alta qualidade produzida nos Estados Unidos, Espanha e Japão é um obstáculo para a inserção dos produtores com menor capital para investimento nesse mercado (Paiva et al., 2004).

Quando o objetivo do melhoramento não é produzir híbridos, o conhecimento da diversidade genética, constatada pelas estimativas da heterose ou por meio da distância genética em cruzamentos, pode auxiliar na escolha de métodos de seleção mais eficientes para explorar esta variabilidade nas gerações avançadas (Paiva et al., 2002). 
As variedades crioulas de melão, também denominadas variedades locais ou landraces, podem ser usadas em programas de melhoramento para ampliação da variabilidade genética com objetivo de seleção de novos tipos e como fontes de genes de adaptação, rusticidade e resistência a estresses bióticos e abióticos.

A Região Nordeste apresenta a maior área cultivada com melão no Brasil, com 13.249 ha cultivados e produção de 332.879 t em 2005. A Região Sul ocupa o segundo lugar, com uma área de 2.392 ha e produção de 14.586 t (Agrianual, 2008).

No Sul do Brasil, parte dos produtores, principalmente os de base agrícola familiar, utilizam variedades crioulas em seus plantios, sendo esta produção destinada para o consumo familiar e para comercialização. Estes agricultores fazem seleção dos frutos que consideram de qualidade superior e produzem a sua própria semente para o cultivo da safra seguinte. Esta seleção, realizada por várias gerações, combinada com a seleção natural, resultou em diversos tipos de melão e em elevada rusticidade e adaptação às condições locais onde foram selecionadas. Devido às suas características de rusticidade, as variedades crioulas são aptas ao cultivo em propriedades de reduzido nível tecnológico e em sistemas agroecológicos.

No Brasil, os trabalhos com recursos genéticos de variedades crioulas de melão são incipientes. Considerando que existem muitas variedades crioulas de melão na Região Sul do país, e que muitas destas variedades já foram perdidas pela alteração da matriz produtiva e pela substituição por cultivares comerciais, é urgente que sejam realizadas ações de coleta, conservação e caracterização.

A caracterização morfológica é um processo que, por meio da utilização de uma lista descritiva, trata de prover maiores informações sobre o germoplasma conservado, dispondo-o de uma forma mais efetiva para a utilização (Ramos et al., 1999). Para promover seu uso, os acessos conservados em Bancos de Germoplasma devem ser bem caracterizados, sem lacunas quanto à efetiva documentação e informação sobre sua origem, características e potencial de uso (Vilela-Morales \& Valois, 2000).

Os Bancos de Germoplasma assumem importância por conservar fonte de genes para o melhoramento genético. No Brasil a conservação de germoplasma de melão é realizada pela Embrapa e por algumas universidades públicas.

As Unidades da Embrapa que conservam esse germoplasma são a Embrapa Clima Temperado, a Embrapa Hortaliças e a Embrapa Semi-Árido. O Banco Ativo de Germoplasma (BAG) de Cucurbitáceas da Embrapa Clima Temperado foi implantado em 2002 e mantém em seu acervo em torno de 400 acessos, sendo que 30 destes são de melão, principalmente variedades crioulas provenientes do Paraná e do Rio Grande do Sul.

O presente trabalho teve por objetivo caracterizar e avaliar a dissimilaridade genética entre variedades crioulas de melão do Sul do Brasil mantidas no BAG de Cucurbitáceas da Embrapa Clima Temperado, por meio da caracterização morfológica dos frutos.

\section{MATERIAL E MÉTODOS}

Foram caracterizados os frutos de 14 acessos de variedades crioulas de melão conservados no BAG de Cucurbitáceas da Embrapa Clima Temperado. Destes acessos, sete foram doados por agricultores do Paraná (C4, C67, C68, C70, C71, C72 e C160), seis foram doados por agricultores do Rio Grande do Sul (C88, C188, C189, C194, C246 e C265) e um (C272) é proveniente de uma banca de comercialização localizada em beira de rodovia do Rio Grande do Sul.

Os acessos foram semeados em setembro de 2006, em recipientes confeccionados com papel jornal e preenchidos com substrato orgânico $(50 \%$ de casca de arroz carbonizada e 50\% de vermicomposto).

As mudas foram transplantadas em outubro do mesmo ano, sendo cultivadas dez plantas por acesso, com espaçamento de $0,5 \mathrm{~m}$ entre plantas e $1,2 \mathrm{~m}$ entre as linhas.

O cultivo foi realizado em campo da Embrapa Clima Temperado, em Cascata-RS, com utilização de adubação orgânica, sem uso de tratamentos fitossanitários, conduzido sem podas e rasteiro. Não foram consideradas bordaduras. Em janeiro de 2007 foram caracterizados morfologicamente cinco frutos maduros por acesso, escolhidos ao acaso.

Foram utilizados 26 descritores de fruto, adaptados a partir de listagem disponível em Esquinas-Alcazar (1983): formato do fruto: (1= globular; $2=$ achatado; $3=$ oblongo; $4=$ elíptico; $5=$ piriforme; $6=$ oval; $7=$ alongado; $8=$ outro formato); gomos do fruto: $(0=$ ausentes; $3=$ superficiais; $5=$ intermediários; $7=$ profundos); textura do epicarpo do fruto: $(1=$ suave; $2=$ granulada; $3=$ enrugada; 4= reticulada; 5= verrugosa; $6=$ com espinhos; $7=$ outra textura); presença de cortiça no epicarpo: $(0=$ ausente; $3=$ esparsa; 5= intermediária; $7=$ densa); padrão da cortiça do epicarpo: $(1=$ longitudinal; $2=$ transversal; $3=$ reticulado; $4=$ pontuado); ruptura do fruto: $(0=$ ausente; $3=$ superficial; $5=$ intermediária; $7=$ profunda); cicatriz floral: ( $3=$ inconspícua; $5=$ intermediária; $7=$ profunda); cor predominante do epicarpo na maturidade: $(1=$ branca; $2=$ verde; $3=$ azul; $4=$ creme; $5=$ amarela; $6=$ laranja; $7=$ vermelha; $8=$ rosa; $9=$ marrom $; 10=$ cinza; $11=$ preta $; 12=$ outra cor); cor secundária do epicarpo na maturidade: $(0=$ ausente; $1=$ branca; $2=$ verde; $3=$ azul; $4=$ creme; $5=$ laranja; $6=$ amarela; $7=$ vermelha; $8=$ rosa; $9=$ outra); desenho produzido pela cor secundária: $(0=$ ausente; $1=$ pontilhado; $2=$ manchado; $3=$ listrado; $4=$ estriado; $5=$ outro); dureza do epicarpo: $(3=$ pouco dura; $5=$ intermediária; $7=$ muito dura); cor interna do epicarpo: $(1=$ branca; $2=$ verde; $3=$ amarela; $4=$ laranja; 5= salmão; 6= outra); intensidade da cor da polpa: $(3=$ clara; $5=$ intermediária; $7=$ escura); textura da polpa: $(1=$ suave-firme; $2=$ granulosa-firme; $3=$ macia; 4= fibrosa-gelatinosa; $5=$ fibrosaseca); sabor da polpa: (3= insípido; $5=$ intermediário; $7=$ adocicado); aroma externo na cicatriz floral: $(0=$ ausente; $1=$ presente); aroma na parte interna do fruto: $(0=$ ausente; $1=$ presente $)$; cor da polpa: $(1=$ branca; $2=$ verde; $3=$ amarela; 4= laranja; 5= salmão); cor da cavidade do fruto: $(1=$ branca; $2=$ verde; 3= laranja; 4= salmão; $6=$ outra cor); cor do tegumento da semente: $(0=$ 
sem tegumento; $1=$ branca; $2=$ amarelo queimado; 3= amarela; 4= laranja; 5= marrom; $6=$ cinza; $7=$ preta); formato da semente: $(1=$ redondo; $2=$ elíptico; $3=$ cordiforme; $4=$ cônico; $5=$ deformado; $6=$ outro formato); comprimento do fruto: $(3=$ curto; $5=$ intermediário; $7=$ longo); largura do fruto: $(3=$ estreito; $5=$ intermediário; $7=$ largo); peso do fruto ( $3=$ leve; $5=$ intermediário; $7=$ pesado); espessura do epicarpo do fruto: $(3=$ pouco espesso; $5=$ intermediária; $7=$ muito espesso); espessura da polpa do fruto: $(3=$ pouco espesso; $5=$ intermediária; $7=$ muito espesso).

As características comprimento, largura e peso do fruto, e espessura de epicarpo e de polpa foram descritas em três estados de descritor. Os estados de descritor foram definidos de acordo com a média e o desvio padrão dos valores medidos na caracterização: curto, estreito, leve e pouco espesso: menor do que a média menos $1 / 2$ desvio padrão; intermediário e pouco espesso: valores compreendidos entre a média dos valores da característica menos $1 / 2$ desvio padrão e a média mais $1 / 2$ desvio padrão; longo, largo, pesado e muito espesso: maior do que a média dos valores da característica mais $1 / 2$ desvio padrão.

Três pessoas, independentemente, realizaram a caracterização de cada acesso. A caracterização foi essencialmente visual, com exceção dos descritores sabor da polpa, aroma externo na cicatriz floral, aroma na parte interna do fruto, comprimento, largura e peso do fruto e espessura do epicarpo e da polpa do fruto.

Os dados obtidos foram submetidos à análise de divergência genética pelo procedimento para dados multicategóricos do programa computacional Genes (Cruz, 2006). Esta metodologia consiste na obtenção de um índice, em que são considerados vários caracteres simultaneamente, sendo que cada caráter pode apresentar estados para cada descritor. Foi gerada uma matriz de dissimilaridade com base no complemento do coeficiente de coincidência simples.

A partir da matriz de dissimilaridade foram formados grupos pelo método de Tocher. A análise de agrupamento baseada no método de otimização de Tocher tem por objetivo a formação de grupos em que os valores das distâncias intragrupos sejam inferiores a quaisquer distâncias intergrupos (Cruz \& Carneiro, 2003).

A matriz de dissimilaridade foi empregada para uso do método hierárquico para formação de um dendrograma com auxílio do programa computacional NTSYSpc 2.10t. (Rohlf, 2000). Foi utilizado o método de agrupamento UPGMA (unweighted pair group mean average).

Nos métodos hierárquicos, os genótipos são agrupados por um processo que se repete em vários níveis, até que seja estabelecido um dendrograma. UPGMA é um método não-ponderado de agrupamento aos pares, utilizando médias aritméticas das medidas de dissimilaridade, que evita caracterizar a dissimilaridade por valores extremos (máximo ou mínimo) entre os genótipos considerados (Cruz \& Carneiro, 2003).

\section{RESULTADOS E DISCUSSÃO}

O caráter formato da semente foi monomórfico, com formato elíptico para todos os acessos caracterizados, tendo sido desconsiderado na análise de dissimilaridade. Assim, dos 26 descritores

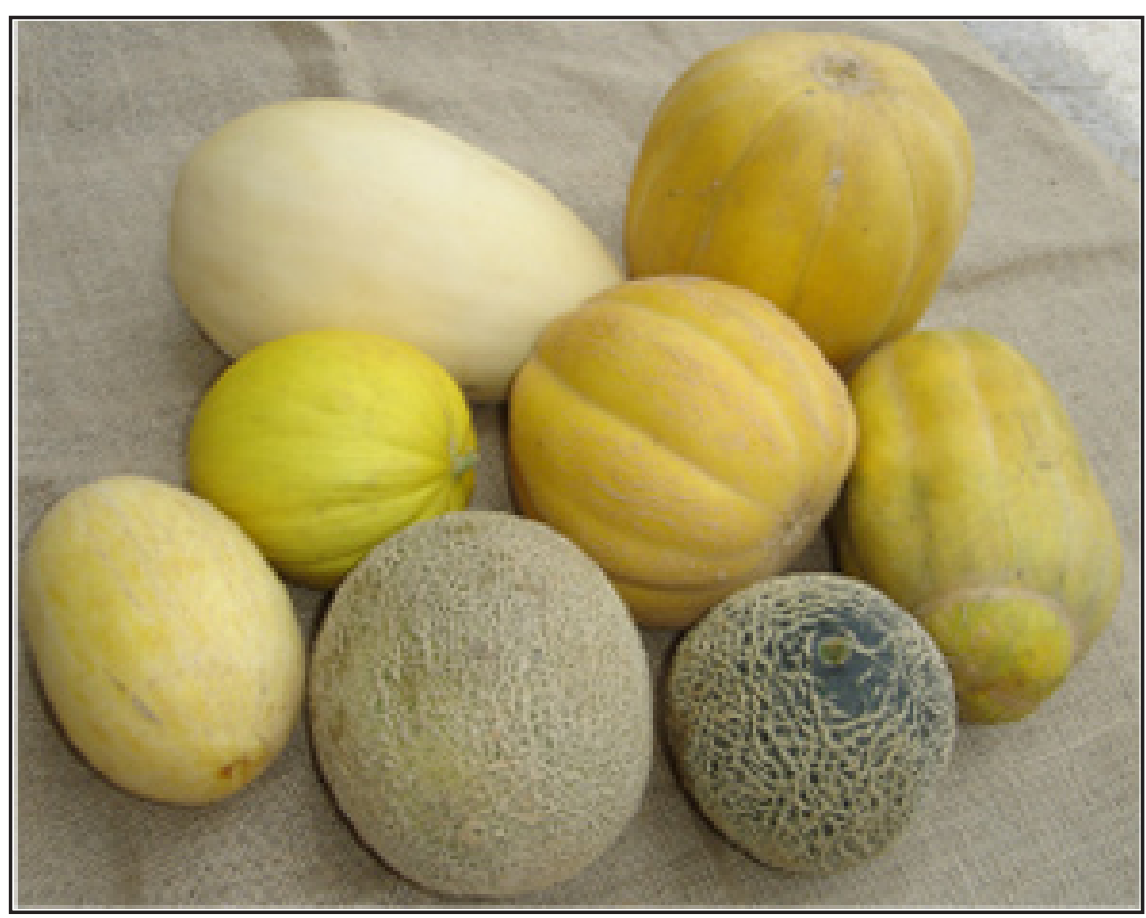

Figura 1. Variabilidade em frutos de diferentes acessos de melão avaliados no presente trabalho (Fruit variability in different melon accessions evaluated in this work). Pelotas, UFPel, 2006. aplicados, foram utilizados os 25 que evidenciaram polimorfismo.

Os acessos de melão (Figura 1) foram agrupados com utilização do método de Tocher, a partir da matriz de distâncias entre variáveis multicategóricas, em dois grupos.

O primeiro grupo foi estabelecido com a maioria dos acessos (C4, C67, C68, C70, C71, C72, C160, C188, C189, C194, C246, C265 e C272) e o segundo grupo foi formado exclusivamente pelo acesso C88. A dissimilaridade média do primeiro grupo foi de 0,5949 e a dissimilaridade entre os dois grupos foi de 0,7908 .

Os acessos C67 e C160 apresentaram o menor coeficiente de dissimilaridade entre si $(0,24)$, com coincidência nos dados para 18 estados de descritor. O segundo menor índice de dissimilaridade foi observado entre os acessos C70 e C72 (0,30), com coincidência nos dados para 17 estados de descritor.

Os acessos C67 e C160 são provenientes do mesmo município, Renasmesma origem. Já os acessos C70 e C72 foram doados pela mesma pessoa. Estes acessos podem ter a mesma origem, as suas sementes podem ter sido misturacença, e provavelmente podem ter a 
das pelo doador ou mesmo terem sido cultivados em locais próximos com cruzamento natural entre os dois acessos, por se tratar de uma espécie alógama.

O par de acessos mais divergentes foi C88 e C188, com 0,96 de dissimilaridade, com a coincidência de apenas um estado de descritor, ambos com presença de aroma externo na cicatriz floral.

$\mathrm{O}$ acesso C88 ficou isolado dos demais, sendo o único entre todos os avaliados que possui formato piriforme e sem gomos, cor de epicarpo creme, cor de polpa branca e ruptura profunda no fruto.

A ruptura do fruto é um caráter altamente indesejável, pois afeta a aparência e diminui drasticamente a durabilidade pós-colheita dos frutos, comprometendo a comercialização. Esta variedade possui características de interesse, como cicatriz da flor inconspícua e polpa muito espessa, entretanto, ela não é recomendada como genitor, pois possui características altamente indesejáveis como ruptura profunda do fruto e sabor insípido. Contudo, se ela for utilizada em cruzamentos, provavelmente deverá ser adotado um método de seleção que permita a eliminação destas características indesejáveis nas progênies. $\mathrm{O}$ acesso C68 apresentou ruptura intermediária e os acessos C7, C72, C188 e C246 apresentaram ruptura superficial.

A maioria dos acessos conteve polpa com cores laranja (C71, C160, C246, C265 e C272) e salmão (C4, C67, C68, C70, C72, C189 e C194). Estas cores apresentam bom aspecto visual para o consumo de seus frutos, especialmente para tipos diferentes daquele conhecido como melão espanhol ou melão amarelo.

Houve supremacia dos acessos em revelarem sabor intermediário, com exceção dos acessos C71, com sabor adocicado, e C246 com sabor insípido. Segundo Miranda et al. (2005), o sabor é a característica sensorial mais importante para os consumidores. $\mathrm{O}$ acesso C71, por possuir sabor adocicado, é o mais indicado para compor blocos de cruzamento quando se pretende incorporar esta característica.

Elevada proporção dos acessos (C4, C68, C70, C71, C72, C189, C265) con-

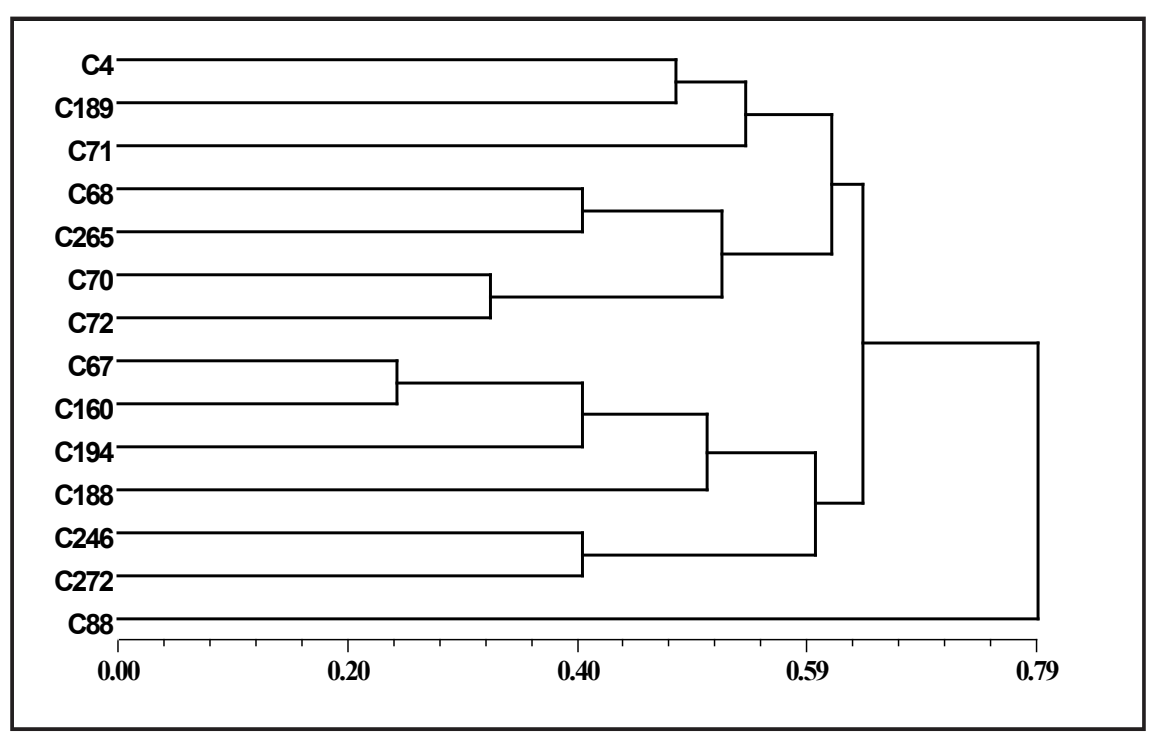

Figura 2. Dendrograma de dissimilaridade genética entre os acessos de variedades crioulas de melão, obtido por meio de matriz de dissimilaridade com uso de dados multicategóricos (Dendrogram of genetic dissimilarity among accessions of melon landraces, obtained by dissimilarity matrix using multicategorical traits). Pelotas, UFPel, 2006.

teve formato oblongo, seguido de globular (C67, C160, C188, C194, C246, C272). O acesso C88 foi o único que não expressou gomos no fruto e C265 foi o único com gomos intermediários. Os demais contiveram gomos superficiais e nenhum dos acessos caracterizados apresentou gomos profundos.

Em relação à cicatriz da flor, os acessos C71 e C272 apresentaram cicatriz profunda, os acessos C4, C70 e C188 cicatriz intermediária e os demais, cicatriz inconspícua. Para comercialização, a presença de cicatriz da flor no fruto, principalmente a profunda, é indesejável por prejudicar o aspecto visual dos frutos.

A média do comprimento dos frutos nos acessos variou de 11,7 (C67) a 26,6 cm (C70 e C88), a média da largura variou de 11,0 (C67) a 15,3 cm (C72). A média do peso dos frutos variou de 0,86 (C67) a 3,5 Kg (C70). A média da espessura do epicarpo dos frutos ficou entre 2,28 (C188) e 7,93 mm (C246), e a média da espessura da polpa dos frutos variou de 2,14 a 3,53 cm (C70). Os acessos C70, C72, C88 e C265 apresentaram os maiores valores para peso dos frutos, caráter desejável por estar relacionada com a produtividade.

A espessura do epicarpo e da polpa dos frutos está relacionada com o rendimento da parte comestível para o consumidor, sendo preferíveis melões com menor espessura de epicarpo e maior espessura da polpa.

Os acessos C4, C72, C68, C188 e C265 apresentaram os menores valores para espessura do epicarpo dos frutos. Os acessos com maior espessura da polpa foram C70, C72, C88, C246 e C272.

$\mathrm{O}$ acesso C72 merece destaque por apresentar elevados valores para peso de fruto e espessura de polpa, com menores valores para espessura de epicarpo, revelando sua superioridade nestes caracteres em relação aos demais acessos caracterizados.

Entre os acessos caracterizados foram encontrados exemplares com todos os estados dos descritores para presença de cortiça no epicarpo, ruptura do fruto, cicatriz da flor, dureza do epicarpo, intensidade da cor da polpa, sabor da polpa, aroma externo na cicatriz floral e aroma interno do fruto.

Os métodos de agrupamento de Tocher e o hierárquico concordaram parcialmente quanto aos grupos formados, pois em ambos, o acesso C88 ficou separado dos demais acessos.

Pelo método hierárquico houve a formação de dois subgrupos (Figura 2), sendo um grupo formado pelos acessos C4, C189, C71, C68, C265, C70 e C72, e outro grupo formado pelos acessos 
C67, C160, C194, C188, C246, C272 e $\mathrm{C} 88$.

Os subgrupos não foram separados pelo agrupamento de Tocher. Isto pode ser explicado por métodos diferentes utilizarem procedimentos distintos para a formação dos grupos. Ambos os métodos (Tocher e hierárquico) utilizados para o estudo da diversidade genética foram parcialmente concordantes.

O uso de descritores multicategóricos foi eficiente para a caracterização dos acessos de melão, o que evidencia que a utilização de variáveis multicategóricas como análise adicional na caracterização de acessos e no manejo de bancos de germoplasma é importante na medida em que é bastante prática e também mais econômica do que as análises moleculares.

Com base nos dados obtidos por meio da caracterização morfológica dos frutos e na análise de dissimilaridade, é possível concluir que existe variabilidade genética entre as 14 variedades crioulas de melão do Sul do Brasil conservados no Banco Ativo de Germoplasma de Cucurbitáceas da Embrapa Clima Temperado.

Os acessos formam dois grupos distintos, sendo que C88 possui características distintas que o colocam em um grupo separado das demais variedades crioulas. Estas variedades crioulas possuem variabilidade para serem usadas em programas de melhoramento genético. Deve ser dado destaque para o acesso C71, por possuir características de interesse como polpa de cor laranja, peso elevado do fruto e sabor adocicado, e para o acesso C72, por possuir bom peso de frutos, pequena espessura do epicarpo e polpa espessa dos frutos.

\section{AGRADECIMENTOS}

À CAPES pela concessão da bolsa de Pós-graduação ao primeiro autor e à Embrapa Clima Temperado pela infraestrutura e suporte financeiro.

\section{REFERÊNCIAS}

AGRIANUAL 2008: Anuário da Agricultura Brasileira. São Paulo FNP. p.393-396.

CRUZ CD. 2006. Programa Genes: análise multivariada e simulação. Viçosa: UFV. $175 \mathrm{p}$.

CRUZ CD; CARNEIRO PCS. 2003. Modelos biométricos aplicados ao melhoramento genético. Viçosa: UFV, v.2, 585p.

ESQUINAS-ALCAZAR JT; GULICK PJ. 1983. Genetic Resources of Cucurbitaceae: a global report. Roma: IBPGR, $101 \mathrm{p}$.

LOPES JF; CARVALHO SIC; PESSOA HBSV. 1999. Recursos Genéticos de melão e pepino na Embrapa Hortaliças. In: QUEIROZ MA; GOEDERT CO; RAMOS SRR. (eds). Recursos genéticos e melhoramento de plantas para o Nordeste Brasileiro Petrolina: EMBRAPA-CPATSA/Brasília: EMBRAPACENARGEN.

MIRANDA NO; OLIVEIRA TS; LEVIEN SLA; SOUZA ER. 2005. Variabilidade espacial da qualidade de frutos de melão em áreas fertirrigadas. Horticultura Brasileira 23: 242-249.

PAIVA WO; LIMA JAA; BUSO GSC; SANTOS
AA; FILGUEIRAS HAC; MOSCA JL; DINIZ FO; COSTA-FILHO AB; SOUZA LC. 2004. Melhoramento genético do melão Cantaloupe na Embrapa Agroindústria Tropical. Boletim de pesquisa e desenvolvimento, Fortaleza: Embrapa Agroindústria Tropical, 14p.

PAIVA WO. 1999. Melhoramento genético de melão. In: QUEIRÓZ MA; GOEDERT CO; RAMOS SRR. (eds.). Recursos genéticos e melhoramento de plantas para o Nordeste brasileiro. (on line). Versão 1.0. PetrolinaPE: Embrapa Semi-Árido/Brasília-DF: Embrapa Recursos Genéticos e Biotecnologia, Disponível em http://www.cpatsa.embrapa. br

PAIVA WO. 2002. Divergência genética entre linhagens de melão e a heterose de seus híbridos. Horticultura Brasileira 2: 34-37.

RAMOS SRR; QUEIRÓZ MA; CASALI VWD; CRUZ CD. 1999. Recursos genéticos de Cucurbita moschata: caracterização morfológica de populações locais coletadas no Nordeste brasileiro. In: QUEIRÓZ MA; GOEDERT CO; RAMOS SRR (eds). Recursos genéticos e melhoramento de plantas para $o$ Nordeste brasileiro. (on line). Versão 1.0. Petrolina-PE: Embrapa Semi-Árido/ Brasília-DF: Embrapa Recursos Genéticos e Biotecnologia. Disponível em http:/www. cpatsa.embrapa.br/catalogo/livrorg/abobora. pdf. Acessado em 10 de abril de 2008.

ROHLF FJ. 2000. NTSYS 2.1: Numerical taxonomic and multivariate analysis system. New York, Exeter Software.

SANTOS AA; CRISÓSTOMO JR; CARDOSO JW. 2004. Avaliação de híbridos de melão quanto às principais doenças nos estados do Ceará e Rio Grande do Norte. Boletim de pesquisa e desenvolvimento, Fortaleza: Embrapa Agroindústria Tropical, 14p.

VILELA-MORALES EA; VALOIS ACC. 2000. Recursos genéticos vegetais autóctones e seus usos no desenvolvimento sustentável. Cadernos de Ciência e Tecnologia 17: 1142. 